\title{
UMA TIPOLOGIA PARA AS INTERJEICCÕES DO PORTUGUÊS BRASILEIRO
}

\section{A TYPOLOGY FOR BRAZILIAN PORTUGUESE INTERJECTIONS}

Renato Miguel BASSO${ }^{1}$

Ariane TEIXEIRA ${ }^{2}$

Resumo: Neste artigo, propomos uma análise sintático-semântica formal das interjeições, segundo a qual elas são indexicais com conteúdo uso-condicional. Em nossa análise, as interjeições recuperam informações contextuais kaplanianas e contribuem para um significado expressivo. Num segundo momento, propomos uma tipologia de algumas interjeições do português brasileiro utilizando como critérios características sintáticosemânticas e chegamos assim a uma classificação linguisticamente motivada das interjeições.

Palavras-chave: Interjeições. Indexicais. Expressões uso-condicionais. Semântica. Sintaxe.
Abstract: In this paper, firstly we propose a formal syntactic-semantic analysis of interjections, according to which these items are indexicals with use-conditional content. In our analysis, interjections recover information from a kaplanian context and contribute to expressive meaning. Secondly, we propose a typology for some Brazilian Portuguese interjections using syntactic-semantic features as our criteria. The result is a linguistically based classification for interjections.

Keywords: Interjections. Indexicals. UseConditional Expressions. Semantics. Syntax.

\footnotetext{
1 Basso. UFSCar. E-mail: rmbasso@gmail.com. ORCID ID: https://orcid.org/0000-0003-2580-0365 2 Teixeira. UFSCar. E-mail: enaira.teixeira@hotmail.com. ORCID ID: https://orcid.org/0000-0002-2357-0300
} 


\section{Introdução}

As interjeições são geralmente definidas pela literatura como uma classe de palavras ${ }^{3}$ aberta e heterogênea, cuja função é expressar sentimentos e emoções do falante. Em geral, as interjeições são exemplificadas por meio de itens como: 'psiu!', 'oba!', 'meu Deus!', 'vixi!', 'tomara!', entre outros itens e construções. Em geral, as interjeições possuem uma sintaxe independente dos outros itens da sentença ${ }^{4}$ e são consideradas apenas vagamente integradas, ou não integradas, aos outros itens linguísticos que compõem uma sentença.

Neste artigo, nossa proposta é apresentar uma forma de análise, tratamento e classificação das interjeições do português brasileiro (doravante PB) nos moldes da semântica e pragmática formal, que trata esses itens como indexicais, cuja contribuição semântica se dá numa dimensão uso-funcional (cf. KAPLAN, 2004; POTTS, 2007, 2005; GUTZMANN, 2019, 2015). Feito isso, proporemos uma tipologia sintático-semântico, segundo essa análise de algumas interjeições do PB.

Para tanto, na seção 1, apresentaremos as nossas hipóteses de trabalho que são: (i) as interjeições são consideradas sentenças completas que possuem elementos indexicais em sua estrutura, recuperados no contexto de fala e (ii) carregam um conteúdo expressivo ou uso-funcional (TEIXEIRA, 2019; BASSO; TEIXEIRA, 2017).

$\mathrm{Na}$ seção 2, apresentaremos um quadro de classificação das interjeições de acordo com as coordenadas contextuais kaplanianas que elas mobilizam, além de alguns outros critérios, como: a necessidade de um interlocutor e/ou ouvinte; se a interjeição acompanha apontamentos ou gestos; quais interjeições selecionam complementos na sentença, entre outros traços/requisitos.

Na terceira seção deste artigo, faremos um balanço do resultado da tipologia proposta na seção 2, e na Conclusão retomaremos o caminho aqui percorrido, bem com apontaremos alguns problemas em aberto.

\footnotetext{
3 "Classe de palavras" ou "classe gramatical" abarca tanto itens isolados como locuções.

4 As interjeições são autônomas com relação às sentenças com as quais aparecem, e por isso são consideradas como sendo independentes e transmitindo conteúdo por si só. Contudo, há exemplos que fogem a essa regra, como é o caso da interjeição 'tomara!', que exprime um conteúdo semelhante a 'eu desejo que p', pois pede um complemento p. Vamos retomar essa interjeição na seção 2.2.
} 


\section{Interjeições como indexicais}

A classe das interjeições é certamente, dentre as classes de palavras tradicionalmente consideradas, aquela que recebeu menos atenção nos estudos linguísticos, e isso é o caso também do ponto de vista da semântica. Muitas vezes tratadas como estando à margem das interações linguísticas propriamente ditas, com um recurso paralinguístico (cf. GOFFMAN, 1981), os membros dessa classe são vagamente descritos como expressando emoções e sentimentos dos falantes, de modo independente do resto da sentença que acompanham, justamente porque, sendo elementos paralinguísticos, não entrariam na composição da sentença.

Contudo, ao longo dos estudos linguísticos essa caracterização superficial foi ganhando contornos mais precisos, nos levando assim a uma imagem mais razoável do funcionamento sintático, semântico e pragmático das interjeições, que dialoga com as teorias linguísticas mais recentes, e as considera efetivamente como parte da gramática de uma língua natural. A abordagem que defenderemos aqui, e que será apresentada nesta seção, se enquadra na tradição de dar às interjeições um conteúdo sintático-semântico, identificando esses itens como um tipo de indexical que veicula um conteúdo específico, que é uso-condicional ou expressivo. No que segue, traremos algumas das principais ideias por trás dessa abordagem e como ela funciona.

Wilkins (1992) é um dos primeiros trabalhos que sistematicamente relaciona interjeições com propriedades encontradas em itens dêiticos (que chamamos aqui de indexicais). Entre as semelhanças notadas está o fato de que boa parte das interjeições estão ligadas ao falante e à situação de fala, numa dependência contextual muito semelhante, por exemplo, à que vemos em itens como 'eu' ou 'isso'. Apesar de pioneiro em sua proposta, Wilkins (1992) não contava com uma teoria semântica robusta e explícita de indexicais; do mesmo modo, o autor nota que as interjeições têm, como adiantamos, independência sintática, sem, contudo, oferecer uma razão para tanto, e conclui que interjeições "valem por sentenças".

Argumentaremos que, usando uma teoria de indexicais como a de Kaplan (1989), é possível explicar o funcionamento semântico das interjeições e também seu comportamento sintático. Sendo assim, vejamos o funcionamento e as características principais da teoria de Kaplan (1989) sobre indexicais para então nos voltar para a estrutura e caracterização das interjeições. 


\subsection{A teoria de indexicais de Kaplan}

Em “Demonstratives" (1989), o filósofo e lógico David Kaplan postulou talvez o que seja ainda a principal teoria sobre itens indexicais nas línguas naturais. Seu trabalho trata, sob o escopo de uma mesma teoria, de aspectos semânticos, lógicos, epistemológicos e metafísicos dos itens indexicais.

Os indexicais são itens linguísticos cuja referência varia em função do contexto; a interpretação de tais itens nos direciona para certas características do contexto, com o objetivo de fixar seu referente num dado proferimento. Segundo Kaplan, os indexicais exploram o contexto de fala ou de proferimento de uma maneira específica, para encontrarem seu referente e só então fazer sua contribuição proposicional.

Dado que na teoria kaplaniana o contexto é responsável por fixar os valores semânticos dos indexicais, podemos justamente olhar para quais são esses valores, segundo propõe o autor, para então chegarmos à sua ideia de contexto. Assim, indexicais ganham uma interpretação ao identificar o agente $\left(\mathrm{c}_{\mathrm{a}}\right)$, o tempo $\left(\mathrm{c}_{\mathrm{t}}\right)$, o lugar $\left(\mathrm{c}_{\mathrm{l}}\right)$, e o mundo $\left(\mathrm{c}_{\mathrm{w}}\right)$ de um dado contexto. Portanto, uma saída interessante é exatamente considerar o contexto como uma unidade informacional composta por dados sobre o agente, o tempo, o lugar e o mundo possível do contexto (outras informações podem ser posteriormente inseridas, mas essas seriam o mínimo).

Na teoria de Kaplan, cada uma dessas informações é chamada de coordenada do contexto, e o próprio contexto é, por sua vez, representado como uma ênupla ordenada (cf. SCHLENKER, 2010; TEIXEIRA, 2012, entre outros):

$$
\mathrm{C}=<\mathrm{C}_{\mathrm{a}^{\prime}}, \mathrm{C}_{\mathrm{t}^{\prime}} \mathrm{C}_{\mathrm{l}^{\prime}} \mathrm{C}_{\mathrm{w}}>
$$

O papel do contexto é fixar os valores (agente, tempo, lugar, entre outros) dos indexicais de um dado proferimento, e uma vez fixados esses valores, os proferimentos que contêm indexicais podem ser avaliados como verdadeiros ou falsos a depender de outros parâmetros, chamados por Kaplan de "circunstancias de avaliação", que são, na verdade, um mundo possível e um tempo.

Assim, Kaplan justifica a dependência dos indexicais de informações específicas do contexto, postulando duas funções para sua computação semântica: o caráter e o conteúdo. Para chegar ao valor semântico de uma sentença, computamos as informações contextuais, e depois seu conteúdo, como no esquema abaixo (cf. SCHLENKER, 2010): 


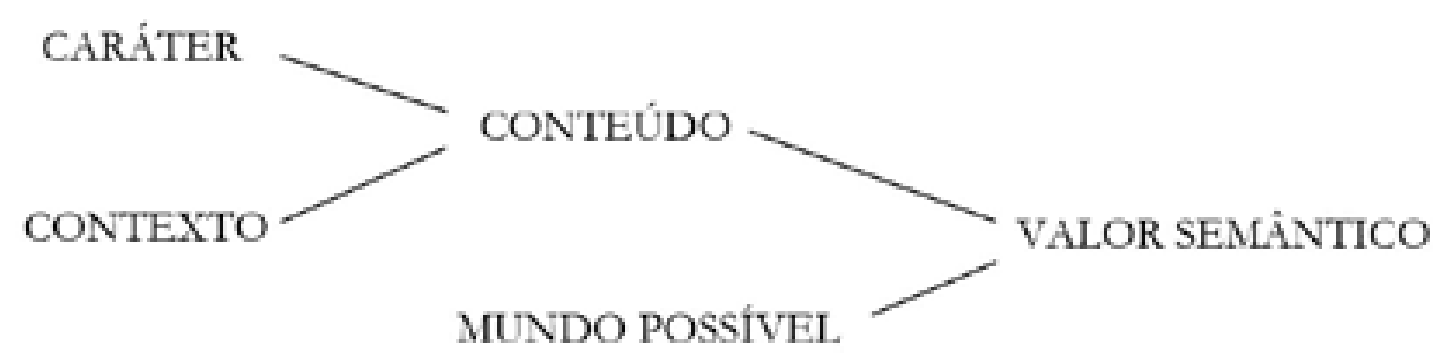

Ou seja, o caráter é função que associa a cada indexical um conteúdo a partir de um dado contexto - é uma função de contexto para conteúdo. Por sua vez, o conteúdo é uma função de mundos possíveis (e tempo) para valores de verdade e responde pelo valor semântico das sentenças ${ }^{5}$.

A seguir, aplicamos essas ideias à interjeição 'oba!', que apresenta um interessante paralelo com, por exemplo, o indexical 'eu' - se não soubermos quem está falando, não sabemos "calcular" o significado do todo, mas teremos apenas as regras de interpretação. Sem sabermos quem é o falante, as sentenças (1) e (2) expressam, grosso modo, o que está em (1a) e (2a), mas se considerarmos que o falante é João, então (1) e (2) expressam o que está em (1b) e (2b):

(1) Eu estou contente.

(1a) O falante está contente.

(1b) João está contente.
(2) Oba!

(2a) O falante está contente.

(2b) João está contente.

É interessante também notar que, se nossa paráfrase estiver correta, a interjeição em (2), 'oba!', de fato "vale por uma sentença" por expressar, como mostra (2b), uma proposição completa. Sendo assim, podemos então explicar também a independência sintática das interjeições - elas "valeriam por" predicados indexicais cujos argumentos são tomados do contexto, como indexicais tomam seus referentes do contexto:

eu

(sintaxe)

(semântica)

Proposição expressa: ESTAR_CONTENTE $\left(c_{a}\right)$ argumento

$\mathrm{C}_{\mathrm{a}}$ estar_contente

predicado função

5 A teoria de Kaplan não aborda somente os indexicais, mas todas as sentenças podem ser tratadas através das funções caráter e conteúdo, de modo que o caráter será uma função constante quando aplicada a itens não indexicais. 


$\begin{array}{lccc} & & & \text { oba! } \\ \text { (sintaxe) } & \text { SENTENÇA } & \text { argumento } & \text { predicado } \\ \text { (semântica) } & \text { PROPOSIÇÃO } & \mathrm{c}_{\mathrm{a}} & \text { função } \\ \text { Proposição expressa: } & \text { ESTAR_CONTENTE }\left(\mathrm{c}_{\mathrm{a}}\right) & & \end{array}$

Assim, uma interjeição faz uma contribuição como um predicado, e recupera seu argumento como um indexical para se saturar - 'oba' vale por ' $\mathrm{C}_{\mathrm{a}}$ estar_contente'. Análises semelhantes podem ser aplicadas para 'ufa!' (c $c_{a}$ estar_aliviado), 'puts!' (c lamentar), etc.

Contudo, essa breve caracterização ${ }^{6}$ não dá conta de um importante aspecto das interjeições, que é o fato de a informação semântica veiculada por elas apresentar uma série de peculiaridades; e é a essas peculiaridades que nos voltamos na próxima seção.

\subsection{Interjeições numa dimensão expressiva: o significado das interjeições}

Até agora, nossa breve análise argumentou a favor de tratar as interjeições como indexicais, e defendeu que elas veiculam um conteúdo proposicional completo. Porém, se a questão fosse somente essa poderíamos esperar que fosse possível substituir interjeições por aquilo que sugerimos como sua paráfrase; dito de outro modo nós poderíamos, sem perda de significado, substituir (2) por (1) - mas este não é o caso. Não podemos, por exemplo, negar (2), mas podemos negar (1):

(3) [João diz:] Não é verdade que eu estou contente.

(4) [João diz:] * Não é verdade que oba.

(1) e (2) têm um conteúdo semelhante, mas cada uma faz sua contribuição em dimensões diferentes de significado - ao passo que (1) é uma sentença com conteúdo descritivo e veri-funcional, (2)é uma sentença com conteúdo expressivo e uso-condicional, ela não pode ser julgada verdadeira ou falsa, mas sim feliz ou infeliz (adequada ou inadequada) para certos contextos de uso, e por isso não se combina como uma negação como 'não é verdade que'.

O estudo desse tipo de expressão ganhou força com o trabalho de Kaplan (2004), e depois, entre vários outros, com os trabalhos de Potts $(2007,2005)$ e Gutzmann $(2019$, 2015). Entre as características do conteúdo uso-funcional está sua dependência da perspectiva de um falante e de um contexto (o que os torna indexicais), o fato de não poderem ser negados e ter sua informação processada assim que proferidos (do mesmo modo que os verbos performativos como 'prometer' e 'jurar').

6 Para uma análise mais completa nessas linhas, cf. Basso e Teixeira (2017) e Teixeira (2019). 
Nossa proposta é que interjeições têm conteúdo expressivo, que pode ser descrito como um predicado veri-condicional - apesar de terem funcionamentos diferentes - cujo argumento é recuperado do contexto por ser um indexical. Em resumo, considerando que interjeições são indexicais que atuam numa dimensão expressiva, sua análise ficaria, em linhas gerais, como abaixo, tomando 'oba!' como estudo de caso:

oba!

Caráter: $\mathrm{c}_{\mathrm{a}}$ está feliz em c (i.e., em $\mathrm{c}_{\mathrm{t}^{\prime}}$ em $\mathrm{c}_{\mathrm{l}}$ e em $\mathrm{c}_{\mathrm{w}}$ )

Conteúdo (descritivo): $\varnothing\left(\approx \mathrm{c}_{\mathrm{a}}\right.$ está feliz)

Conteúdo expressivo: e está feliz ${ }^{7}$

O que a descrição acima captura é o fato de que 'oba!' tem um caráter kaplaniano - uma função de contextos para conteúdos -, expresso por ' $\mathrm{c}_{\mathrm{a}}$ está feliz em c (i.e., em c $\mathrm{c}_{\mathrm{t}^{\prime}}$ em $c_{1}$ e em $c_{w}{ }^{\prime}$. Porém, o resultado da função caráter é um conteúdo que se dá numa dimensão expressiva, notado como 'e está feliz', de modo que o conteúdo descritivo é nulo $(\varnothing)$, apesar de corresponder informacionalmente à 'c está feliz', conforme indicamos $\mathrm{com}^{\prime} \approx \mathrm{c}_{\mathrm{a}}$ está feliz'. Em outras palavras, itens como interjeições têm conteúdo expressivo, mas seu funcionamento é similar ao dos outros indexicais.

Como comparação, podemos colocar os itens 'oba!' e 'eu' - um indexical canônico/descritivo - lado a lado; é o que fazemos no quadro que segue:

\begin{tabular}{|l|l|}
\hline \multicolumn{1}{|c|}{ oba! } & \multicolumn{1}{|c|}{ eu } \\
Caráter: $\mathrm{c}_{\mathrm{a}}$ está feliz em c & Caráter: $\mathrm{c}_{\mathrm{a}}$ \\
Conteúdo (descritivo): $\varnothing\left(\approx \mathrm{c}_{\mathrm{a}}\right.$ está feliz) & Conteúdo (descritivo): $\mathrm{e}$ \\
Conteúdo expressivo: e está feliz & Conteúdo expressivo: $\AA$ \\
\hline
\end{tabular}

Como podemos ver pela comparação acima, as interjeições não teriam conteúdo descritivo - por isso não podem ser verdadeiras ou falsas -, apesar de terem um conteúdo semântico que pode ser associado a um conteúdo descritivo. Por sua vez, os indexicais canônicos não teriam conteúdo expressivo algum e somente conteúdo descritivo.

7 Nesta formulação, 'e' está pelo tipo lógico de indivíduo, que é a contribuição do indexical.

8 Como vimos, na teoria de Kaplan (1989), todos os itens das línguas naturais seriam interpretados pela função caráter, mas à exceção dos indexicais o resultado seria constante para todos os outros itens, por isso, não há problema em considerar o predicado 'estar feliz' como parte do caráter de 'oba!'. 
O quadro comparativo abaixo leva em conta dados de itens descritivos, expressivos e indexicais em dois tipos de discurso reportado - direto e indireto ${ }^{9}$; a análise dos exemplos serve como argumento da análise que propomos aqui:

\begin{tabular}{|c|l|}
\hline \multicolumn{1}{|c|}{$\begin{array}{c}\text { Expressivo/interjeição } \\
\text { oba! }\end{array}$} & \multicolumn{1}{c|}{\begin{tabular}{c}
\multicolumn{1}{|c|}{ Indexical } \\
eu
\end{tabular}} \\
$\begin{array}{l}\text { (5) João: Maria disse "oba!" } \\
(6) \text { * João: Maria disse que oba! }\end{array}$ & $\begin{array}{l}\text { (7) João: Maria disse "eu tô com fome" } \\
\text { (8) João: Maria disse que eu tô com fome }\end{array}$ \\
\hline droga (de) $)^{10}$ & \multicolumn{1}{|c|}{$\begin{array}{c}\text { Descritivo } \\
\text { a Lua é feita de queijo }\end{array}$} \\
$\begin{array}{l}\text { (9) João: Maria disse "Desliga essa droga } \\
\text { de TV!" } \\
\text { (10) João: Maria disse que é para desligar } \\
\text { essa droga de TV" }\end{array}$ & $\begin{array}{l}\text { (11) João: Maria disse "a Lua é feita de } \\
\text { queijo" } \\
\text { (12) João: Maria disse que a Lua é feita de } \\
\text { queijo }\end{array}$ \\
\hline
\end{tabular}

O indexical (não-expressivo) 'eu' apresenta um comportamento diferenciado a depender de estar num discurso reportado direto ou indireto ${ }^{12}$; note que 'eu', em (7), não é interpretado como se espera, ou seja, como sendo equivalente ao agente do contexto de proferimento $\left(\mathrm{c}_{\mathrm{a}}\right)$, mas sim como o agente do proferimento reportado, que, para o caso de (7) é Maria. Por sua vez, o 'eu' em (8) é interpretado como o esperado, i.e., como c $\mathrm{a}_{\mathrm{a}^{\prime}} \mathrm{e}$ se refere ao agente do proferimento, que, nesse caso, é João. Para deixar esse contraste mais claro, podemos lançar mão das seguintes paráfrases $\left(7^{\prime}\right)$ e $\left(8^{\prime}\right)$, abaixo:

$\left(7^{\prime}\right)$ João: Maria disse que ela $a_{i}$ está com fome.

(8') João: $\mathrm{M}_{\mathrm{i}}$ Maria ${ }_{\mathrm{j}}$ disse que $\mathrm{eu}_{\mathrm{i} / *_{\mathrm{j}}}$ tô com fome.

Para o caso de sentenças que reportam um conteúdo simplesmente descritivo que também não envolva indexicais, como 'a Lua é feita de queijo', sua contribuição é

9 Nos exemplos que seguem a formulação "João:" simplesmente indica que João é o agente (i.e., falante) do proferimento que segue o sinal ":".

10 Não lidamos com esse tipo de expressivo aqui, que foi extensamente trabalhado por Potts $(2007,2005)$ e Gutzmann (2019, 2015), para o inglês. Julgamos que a discussão que faremos na sequência é suficiente para explorar esse tipo de item em contraste com as interjeições. Para uma análise das interpretações expressivas dos diminutivos no espanhol, ver Fortin (2011).

$11 \mathrm{O}$ ajuste sintático feito aqui, i.e., 'é para', não interfere em nosso foco - 'droga (de)' e sua interpretação.

12 Os casos de discurso reportado direto exemplificam situação de "quase-citação", e é por isso que na escrita são destacados pelo uso de aspas - seu funcionamento não é, num certo sentido, natural, e exige recursos diferenciados para serem interpretados. 
sempre a mesma, independentemente de termos um discurso reportado direto (como em (11)) ou indireto (como em (12)).

Assim, mostramos que indexicais são sensíveis ao tipo de discurso reportado. Como expressivos são um tipo de indexical, a expectativa é que eles também se comportem diferentemente a depender do tipo de discurso reportado envolvido. E, de fato, é exatamente isso o que vemos com os exemplos em (5)-(6) e (9)-(10).

Para (9), no discurso direto, o expressivo 'droga (de)' está ligado à Maria que é o agente do discurso reportado, e não a João, que é o agente do proferimento; por isso, sabemos que quem tinha uma atitude negativa quanto ao fato de a TV estar ligada com (9) é Maria, e não João ${ }^{13}$. Podemos indicar isso, informalmente, com a paráfrase abaixo, na qual aparece o índice "i":

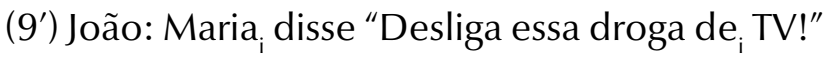

No entanto, com (10) a interpretação é ligeira mais importantemente diferente nesse caso, podemos atribuir a atitude negativa tanto a João quanto a Maria; logo, há aqui uma interpretação, talvez a mais saliente delas, que liga o expressivo ao agente do proferimento, do mesmo que 'eu' em (8) está ligado, como é de se esperar, ao agente do proferimento. A paráfrase abaixo captura esse fato:

(10') João: Maria ${ }_{\mathrm{j}}$ disse que para desligar essa droga $\mathrm{de}_{\mathrm{i} / \mathrm{j}}$ TV.

Como adiantamos, devíamos esperar um contraste semelhante para os expressivos que são interjeições. Contudo, ao voltarmos para os exemplos (5) e (6), repetidos abaixo, o que temos é a inaceitabilidade de interjeições em discurso reportado indireto:

(5) João: Maria disse "oba!"

(6) * João: Maria disse que oba!

A interjeição reportada em discurso direto em (5) se comporta como os demais indexicais vistos anteriormente - liga-se ao agente do discurso reportado, ou seja, em (5), quem está feliz é Maria. De fato, em todos os casos de discurso reportado direto nos quais havia um elemento indexical, esse elemento, ao invés de se relacionar ao agente do contexto de proferimento, se ligou invariavelmente ao agente do contexto reportado (i.e., Maria para os exemplos trabalhados).

13 Segundo Potts $(2007,2005)$, e diversos outros autores que se debruçaram sobre o tema, expressivos desse tipo são, via de regra, ligados ao agente do proferimento, como é o caso com indexicais em geral. 
A expectativa é que a interjeição em discurso reportado indireto se relacione ao agente do proferimento - de modo semelhante ao que vimos com 'eu' e com 'droga (de)'. Porém, como o exemplo (6) evidencia, essa expectativa não se concretiza, pois o resultado de termos uma interjeição em discurso reportado é uma sentença agramatical. Como então explicar essa situação?

A saída, como sugerimos, está justamente em assumir que interjeições têm somente conteúdo expressivo. Some-se a isso o fato, exemplificado com as sentenças acima e defendido por Kaplan (1989), que, em discurso reportado indireto, o que temos é o conteúdo (descritivo) de um indexical, nunca seu caráter. Se isso estiver correto, a expectativa é que interjeições não gerem sentenças bem-formadas quando estão em discurso reportado indireto, pois não possuem um conteúdo descritivo com o qual contribuir para a sentença (como um todo) na qual aparecem. Em resumo, (i) o conteúdo (kaplaniano) de uma interjeição é totalmente expressivo e se dá num determinado contexto de proferimento; (ii) seu conteúdo é também formado por informações indexicais recuperadas do contexto de proferimento em que são empregadas; (iii) em um discurso reportado indireto, encontramos apenas conteúdos descritivos; (iv) logo, uma interjeição num discurso reportado indireto não tem conteúdo descritivo com o qual contribuir, gerando a estranheza ou agramaticalidade do todo.

Para completar a explicação, é importante entendermos as razões de termos expressivos como 'droga (de)' em discurso indireto - essa possibilidade é um tanto surpreendente se considerarmos que estamos também diante de expressivos.

Contudo, há importantes diferenças entre 'oba!' e 'droga (de)' - na verdade, entre interjeições e itens expressivos que se comportam como predicados. A maior dessas diferenças é justamente o fato de que as interjeições são itens sintaticamente independentes e completos, que equivalem a sentenças, não tendo, portanto, composição interna do ponto de vista sintático, mas apenas de seu conteúdo semântico.

Por sua vez, expressivos como 'droga (de)' são um tipo de predicado que se aplicam a um dado argumento, e são, portanto, sintaticamente incompletos ${ }^{14}$. A existência de algum tipo de conteúdo descritivo para esses itens, ao lado de seu conteúdo expressivo, permite que esses itens apareçam em discurso reportado indireto, funcionando exatamente como o indexical 'eu', e seu conteúdo expressivo se dá justamente no contexto de proferimento, e não se relaciona com o contexto de proferimento reportado. Tal fato permite entender por que as interjeições não aparecem em discurso reportado - elas não têm conteúdo descritivo algum, e esses ambientes só recebem conteúdo descritivo.

14 A composicionalidade sintática dá a esse tipo de item algum conteúdo descritivo, que pode impor, por exemplo, restrições que a gramática gerativa conhece como c-seleção e s-seleção. 
Assim sendo, é possível (i) lidar com as interjeições no âmbito das teorias formais sobre o significado linguístico, e considerando que (ii) as interjeições são um tipo particular de indexical. Com essa descrição do comportamento das interjeições, vejamos então como classificar algumas das mais comumente usadas no PB, chegando a um quadro mais completo sobre as interjeições por meio da análise empregada aqui.

\section{Tipologia das interjeições}

Para fazer uma tipologia das interjeições do PB, optamos por selecionar aquelas que são mais mencionadas nas gramáticas tradicionais ${ }^{15}$. A seleção das interjeições foi realizada da seguinte maneira: em primeiro lugar, selecionamos 4 (quatro) gramáticas tradicionais do PB comumente usadas no Brasil são elas: Gramática da Língua Portuguesa (CIPRO NETO, 1998), Gramática contemporânea da língua portuguesa (DE NICOLA; INFANTE, 1997), Gramática em textos (SARMENTO, 2005), Gramática (FARACO; MOURA; MARUXO JR., 2007) e 1 (um) site Só Português ${ }^{16}$ referente à gramática tradicional.

A escolha dessas quatro gramáticas e do site foi feita pelo fato de que fundamentalmente essas obras focam na perspectiva da gramática tradicional do português abordando as dez classes gramaticais, sendo que a última classe é a das interjeições, além de serem amplamente (re)conhecidas e usadas como referência no Brasil. Isso não significa, obviamente, que essas sejam as únicas interjeições do PB e nem aquelas mais usadas, mas ainda podem servir como um referencial mínimo.

O material consultado classifica as interjeições de acordo com sentimentos ou apelos que expressam. A lista de classificação não é padrão, pois "como uma mesma interjeição pode expressar várias emoções, qualquer lista que se faça está sujeita a falhar" (DE NICOLA; INFANTE, 1997, p. 236). Portanto, além de as interjeições carecerem de uma definição que condiz com sua funcionalidade, elas também necessitam de uma classificação que use critérios que abarquem sua tipologia heterogênea e que sejam linguisticamente significativos, com algum lastro teórico.

Os sentimentos e os apelos mais recorrentes nas gramáticas para classificar as interjeições são: advertência, alegria, alívio, chamamento, concordância, desaprovação, desejo, dor, dúvida, impaciência, medo, pedido de silêncio, espanto, aplausos, saudação e surpresa.

15 A opção por essas gramáticas tem a ver com a grande variação regional entre as interjeições usadas no Brasil, numa tentativa de buscar alguma estabilidade pelo menos naquilo que, consensualmente, estamos dispostos a chamar de interjeições. Obviamente, em pesquisas futuras o inventário deve ser ampliado com base em outros dados; seja como for, as descrições e conclusões teóricas devem se manter.

16 Disponível em: http://www.soportugues.com.br/secoes/morf/morf90.php. Acesso em: 06 set. 2019. 
Há, por um lado, alguns sentimentos que aparecem menos (impaciência, aprovação, piedade e cansaço), e há, por outro lado, sentimentos que aparecem como sinônimos (admiração ou espanto, apelo ou chamamento, aversão ou contrariedade, dúvida ou incredulidade, piedade ou lamento, reprovação ou desacordo) (SARMENTO, 2005). A definição vaga, segundo a qual as interjeições expressam sentimentos e emoções do falante, consequentemente se reflete em sua classificação, que mobiliza, ao menos, 20 (vinte) sentimentos diferentes.

Como dito anteriormente, não há diretrizes a serem seguidas na classificação desses itens nas obras consultadas. E parece que o motivo para tanto é que algumas interjeições possuem mais de um significado, ou seja, uma interjeição pode estar relacionada a mais de um sentimento ou apelo, como 'upa!', que aparece tanto na classificação de espanto ou surpresa como em estímulo (CIPRO NETO, 1998). Contudo, a pluralidade de significado de algumas interjeições não é motivo suficiente para não estabelecer parâmetros de classificação.

Podemos aplicar os critérios de classificação a qualquer lista de interjeições, pelo fato de todas elas, em princípio, compartilharem as mesmas características. Como não conseguiríamos fazer uma lista de todas as interjeições existentes, e também não é o objetivo deste trabalho, selecionamos as interjeições usando a seguinte metodologia: (i) pesquisamos as gramáticas e o site em busca das interjeições; (ii) selecionamos as interjeições que apareciam em pelo menos 3 obras diferentes; (iii) e assim chegamos a 30 interjeições para analisarmos.

As interjeições que cumprem tais critérios são: 'viva!', 'psiu!', 'avante!', 'ah!', 'oba!', 'fora!', 'puxa!', 'arre!', 'tomara!', 'ai!', 'ui!', 'credo!', 'cuidado!', 'atenção!', 'vamos!', 'oh!', 'ufa!', 'bravo!', 'pois sim/não!', 'silêncio!', 'toca!', 'calma!', 'putz!', 'vixe!', 'coragem!', 'força!', 'hãhã!', 'opa!', 'raios!' e 'caramba!'.

Como mencionamos, algumas interjeições possuíam mais de uma classificação por gramática; por exemplo, a interjeição 'ah!' está tanto na classificação de "alegria ou satisfação" quanto "espanto ou admiração" (Só Português, acesso dia 06/09/2019). Há construções que são consideradas interjeições, como 'o quê!', 'essa não!' e 'pobre de mim!' (SARMENTO, 2005), mas que não aparecem em todas as gramáticas, e, como essas interjeições não são recorrentes, decidimos não as usar.

Partindo dessa lista de interjeições, vamos considerar três conjuntos de critérios em nossa classificação: (i) o primeiro deles, que veremos na seção 2.1, tem a ver com a proposta de Ameka (1992), que talvez seja a primeira tipologia de interjeições linguisticamente motivada, e procura classificar tanto a natureza do item em análise 
(se interjeição primária ou secundária), quanto à natureza da contribuição semântica; (ii) o segundo conjunto de critérios, explicitados na seção 2.2., tem a ver com a estrutura sintático-semântica das interjeições, e aqui nos perguntaremos se a interjeição pede algum tipo de complemento sentencial, ou se pode, por exemplo, ser repetida; finalmente, (ii) a seção 2.3 trará critérios que têm a ver com sua natureza indexical e nos perguntaremos quais coordenadas contextuais são mobilizadas por uma dada interjeição.

\subsection{Critérios extraídos de Ameka (1992)}

Para Ameka (1992), a primeira distinção entre interjeições as divide em primárias e secundárias: as primárias são aqueles itens que pertencem somente à classe das interjeições e as secundárias são compostas por um ou mais itens linguísticos que pertencem a alguma outra categoria gramatical, mas podem ser usadas como interjeição. Ao separar nossas 30 interjeições em primárias e secundárias, temos o seguinte quadro:

Quadro 1. Interjeições primárias e secundárias

\begin{tabular}{|l|l|}
\hline $\begin{array}{l}\text { Interjeições } \\
\text { primárias }\end{array}$ & $\begin{array}{l}\text { 'psiu!', 'ah!', 'oba!', 'puxa!', 'arre!', 'tomara!', 'ai!', 'ui!', 'oh!', 'ufa!', } \\
\text { 'bravo!', 'putz!', 'vixe!', 'pois sim/não!', 'hã-hã!', 'opa!', e 'caramba!' }\end{array}$ \\
\hline $\begin{array}{l}\text { Interjeições } \\
\text { secundárias }\end{array}$ & $\begin{array}{l}\text { 'viva!', 'fora!', 'credo!', 'cuidado!', 'atenção!', 'vamos!', 'silêncio!', } \\
\text { toca!', 'calma!', 'coragem!', 'força!', e 'raios!', 'avante!' }\end{array}$ \\
\hline
\end{tabular}

Fonte: Elaboração própria

Ao passo que essa classificação é intuitiva para alguns casos - vemos interjeições primárias em 'ai'! e 'ufa!' e secundárias em 'meu deus!' e 'cuidado!' -, há também casos mais problemáticos. Assim, considerando a definição de interjeição secundária (i.e., qualquer item usado como interjeição que tenha outro uso em outra classe gramatical), encontramos alguns casos que geram incertezas, como 'puxa!', 'opa!', 'avante!' e 'raios!'; abaixo, vamos falar de cada um desses casos.

A forma 'puxa' pode ser relacionada ao verbo 'puxar' (a forma da terceira pessoa do singular do presente do indicativo e a da segunda pessoa do singular do imperativo), e isso poderia nos levar a classificar 'puxa' então como uma interjeição secundária. No entanto, não usamos essa interjeição com o sentido do verbo 'puxar', e, portanto, a interjeição 'puxa!' não compartilha o mesmo campo semântico da forma do verbo nem é percebida pelos falantes como tal, e assim ela é uma interjeição primária. Algo semelhante 
acontece com a interjeição 'opa!'; se formos consultar 'opa!' no dicionário ${ }^{17}$ veremos que se trata de uma forma de conjugação do verbo 'opar'. Contudo, mais uma vez, o falante não remete ao sentido do verbo quando profere a interjeição ('opar' possui o sentido de inchar, intumescer). Então, podemos classificar 'opa!' como uma interjeição primária. ${ }^{18}$

Por sua vez, 'avante!'19 compartilha do mesmo campo semântico do advérbio, dado que o sentido é adiante, para frente. Portanto, nesse caso, podemos de fato dizer que se trata de uma interjeição secundária. Outro exemplo é a interjeição 'raios!', que remete a um substantivo que denota um fenômeno meteorológico, e assim, seguindo o mesmo raciocínio, trata-se de uma interjeição secundária.

A distinção entre interjeição primária e secundária não se esgota numa coincidência sonora de formas, mas sim de significados próximos, encontrados numa mesma forma, e sendo assim é de esperar que encontremos casos limítrofes.

Ameka (1992) fornece também uma classificação baseada na funcionalidade semântica das interjeições em contextos efetivos/concretos de fala. Segundo o autor, podemos classificar as interjeições como: expressivas ${ }^{20}$, conativas ou fáticas.

As interjeições expressivas são aquelas que têm a ver com o estado emocional e mental do falante e são divididas em: emotivas e cognitivas. As emotivas expressam as emoções do falante, como alegria, tristeza, raiva, surpresa, dor, espanto, entre outros. Não cabem apelos, intenção de chamar alguém, pedido de silêncio, auxílio ou desculpa, entre outros. Por sua vez, as cognitivas expressam o estado mental ou de compreensão do falante. No quadro a seguir, trazemos uma possibilidade de quais interjeições se encaixam nesses critérios:

17 Segundo o dicionário Priberam online, 'opar' significa “inchar", "intumescer". Acesso em: 06 set. 2019.

18 Só para exemplificar mais um caso, a interjeição 'tomara!' é usada comumente em casos em que o falante quer expressar o desejo de que algo se realize. Logo, esse item não remete ao sentido do verbo 'tomar', e portanto é uma interjeição primária.

19 Esta interjeição, como outras, pode ser um imperativo; contudo, não é o nosso foco se estender sobre as semelhanças e as diferenças entre as interjeições e imperativos. Este é um interessante tema a ser pesquisado no futuro.

20 Ameka (1992, 2006), assim como Wierzbcka (1992), usa o termo 'expressivo' para categorizar as interjeições de acordo com as suas funções e salienta que as interjeições expressam o estado emocional do falante. Tem alguma relação com significado expressivo à la Kaplan (2004) e Gutzmann (2015, 2019), mas há também muitas diferenças e é importante manter cada um dos termos dentro de sua tradição. 
Quadro 2. Interjeições expressivas emotivas e cognitivas

\begin{tabular}{|l|l|}
\hline $\begin{array}{l}\text { Interjeições expressivas } \\
\text { emotivas }\end{array}$ & $\begin{array}{l}\text { 'viva!', 'avante!', 'oba!', 'puxa!', 'arre!', 'ai!', 'ui!', 'credo!', } \\
\text { 'ufa!', 'opa!', 'calma!', 'vixe!', 'raios!', 'caramba!' e 'putz!' }\end{array}$ \\
\hline $\begin{array}{l}\text { Interjeições expressivas } \\
\text { cognitivas }\end{array}$ & 'ah!', 'puxa!', 'caramba!', 'ai!', 'ui!', 'vixe!' e 'opa!' \\
\hline
\end{tabular}

Fonte: Elaboração própria

Ressaltamos que na categoria de "interjeições expressivas emotivas" não estamos levando em consideração quais são os tipos de emoções ou sentimentos que esses itens veiculam, mas apenas que essa é a função de um subconjunto das interjeições.

Dentro do nosso quadro de 30 interjeições, temos muitos itens que expressam sentimentos e emoções, porém nem todas. As interjeições que ficaram de fora dessa classificação são 'cuidado!', 'atenção!', 'fora!', 'coragem!', 'silêncio!', 'força!', 'psiu!', 'tomara!', 'vamos!', 'bravo!', 'toca!', essas expressam algum pedido, desejo, ordem, ou aprovação, e não cabem na classificação acima.

No que concerne às "interjeições expressivas cognitivas", esses itens estão voltados ao estado cognitivo ou ao pensamento do falante. Segundo a nossa seleção de interjeições, podemos exemplificar esse critério com itens, como 'ah!', 'puxa!', 'caramba!', 'vixe!' e 'opa!'.

Por sua vez, as interjeições conativas são dirigidas a um locutor, portanto, necessariamente pedem um ouvinte, em geral com a intenção de atrair sua atenção, exigindo resposta ou ação. O quadro abaixo traz as interjeições conativas da nossa seleção:

Quadro 3. Interjeições conativas

\begin{tabular}{|l|l|}
\hline \multirow{2}{*}{ Interjeições conativas } & $\begin{array}{l}\text { 'psiu!', 'avante!', 'fora!', 'cuidado!', 'atenção!', 'vamos!', } \\
\text { 'bravo!', 'pois sim/não!', 'tomara!', 'silêncio!', 'toca!', 'calma!', } \\
\text { 'coragem!', 'força!' e 'hã-hã!' }\end{array}$ \\
\hline
\end{tabular}

Fonte: Elaboração própria

Esse critério avalia a necessidade de um ouvinte para o uso adequado de uma dada interjeição, e assim caímos num requisito importante que é necessidade versus possibilidade de um ouvinte/interlocutor. 
As interjeições elencadas nessa categoria necessitam de um ouvinte e, portanto seria estranho ou inadequado alguém proferir 'silêncio!' sozinho, ou alguém dizer 'fora!' em um ambiente ou contexto em que não há mais ninguém (salvo casos de alucinações, mas mesmo em tais casos, o uso da interjeição é igual, pois o falante considera que há, de fato, um interlocutor).

Imagine a seguinte situação: o falante está sozinho quando uma barata passa por ele, sua reação então é gritar 'credo!', e a mesma reação pode acontecer se tiver mais pessoas no ambiente. Outra circunstância que podemos vislumbrar é o falante estar ou não sozinho e ocorrer de ele quebrar um copo e proferir 'putz!'; esses e outros cenários nos levam a não colocar as outras interjeições na categoria conativa, pois para esses itens há somente a possibilidade de ter um ouvinte e não a necessidade.

Finalmente, segundo Ameka (1992), as interjeições fáticas são usadas para manter o fluxo da conversa, e assim, mais uma vez, a presença de um ouvinte é obrigatória. Vejamos no quadro abaixo as interjeições fáticas de nossa seleção:

Quadro 4. Interjeições fáticas

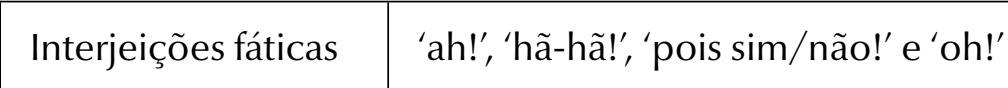

Fonte: Elaboração própria

Essas interjeições, apesar de terem a função de manter o fluxo conversacional, não podem ser confundidas com marcadores discursivos, que são elementos linguísticos cuja função é amarrar as ideias textuais estabelecendo elos coesivos entre as partes dos textos no plano interpessoal, mantendo a interação falante/ouvinte e auxiliando no planejamento da fala (FREITAG, 2007)21. Por seu turno, as interjeições fáticas são como uma resposta do falante ao interlocutor de que ele está prestando atenção no desenvolvimento da conversação.

Em resumo, os critérios que apresentamos até o momento são uma reinterpretação e reelaboração de critérios sugeridos no trabalho de Ameka (1992), que classifica as interjeições de acordo com sua funcionalidade. Nesse panorama, podemos afirmar que as interjeições não expressam somente sentimentos e emoções do falante, mas cumprem outras funções na língua. A seguir, vamos apresentar outros critérios baseados no contexto de fala segundo a teoria kaplaniana.

21 Como 'tá', 'né' e 'daí' em: "Eu vi tudo, tá?"; "Eu comprei o livro, né?"; “Daí, o João chegou na hora". 


\subsection{Outros critérios: complementos, gestos, repetição e mais de um significado}

Esses critérios têm a ver com o comportamento gramatical das interjeições, do ponto de vista sintático e semântico. Vamos começar pelo critério de a interjeição selecionar complementos; as interjeições, como nós dissemos até agora, possuem sua "carga semântica" própria, ou seja, elas têm seu sentido próprio sem entrar em composição com outros elementos da sentença. Dito isso, em nossa lista, há uma interjeição que pede um argumento - trata-se de 'tomara!'.

A interjeição 'tomara!'22, assim como outras interjeições de significados semelhantes, carrega seu próprio sentido expressivo, e podemos substituí-la por uma estrutura semanticamente equivalente como 'eu desejo que p'. Usando tal construção, teríamos uma paráfrase mais próxima para capturar a informação semântica da interjeição 'tomara'. Vejamos o seguinte exemplo:

(13) Tomara que amanhã chova.

Podemos interpretar semanticamente o que é expresso como sendo a proposição 'eu desejo que amanhã chova'; assim, temos o agente do contexto ('eu') que é preenchido no contexto de proferimento kaplaniano; o verbo desejar pede um complemento; tal complemento tem que ser uma proposição $p$, e, assim sendo, $p$ faria parte do conjunto de desejos do falante do proferimento; $p$ pode estar presente no proferimento do falante ou ser recuperado a partir do contexto de fala compartilhado entre os locutores.

Dado que nenhuma outra interjeição precisa de complemento da mesma natureza, poderíamos indagar se tal item é de fato interjeição. Contudo, este é apenas um critério, e não é suficiente para tirar 'tomara!' da classe das interjeições, pois, como veremos, esse item possui conteúdo expressivo e responde positivamente a outros critérios. Assim, uma saída é sugerir que há pelo menos uma interjeição que não é sintaticamente independente, e aqui consideraremos 'tomara' como uma interjeição que tem uma estrutura argumental preenchida por conteúdos indexicais e proposicionais ${ }^{23}$.

Outro critério de classificação é se a interjeição é ou não acompanhada de um gesto ou de um apontamento ${ }^{24}$. Este critério está relacionado ao caráter paralinguístico de certos itens, ou seja, fatores como gestos, expressões faciais, entonação, entre outros, que estão

22 E similares em significado, como 'oxalá!', 'que Deus queria!', entre outras.

23 Há, obviamente, muito mais a ser dito sobre 'tomara', mas aqui ficaremos com essa breve definição.

24 Interjeições são usadas também na escrita, o que traz importantes e interessantes questões para esse critério que, aqui, não abordaremos. 
- | Uma tipologia para as interjeições do português brasileiro

ligados à modalidade não verbal, e que entram na interpretação desses itens ${ }^{25}$. Há de fato algumas interjeições que vêm acompanhadas de apontamentos ou gestos; vejamos o quadro, seguido de alguns exemplos:

Quadro 5. Interjeições que acompanham gestos ou apontamentos

\begin{tabular}{l|l}
$\begin{array}{l}\text { Interjeições que acompanham gestos ou } \\
\text { apontamentos }\end{array}$ & $\begin{array}{l}\text { 'cuidado!', 'bravo!', 'psiu!', 'fora!' e } \\
\text { 'silêncio!' }\end{array}$
\end{tabular}

Fonte: Elaboração própria

(14) Cuidado! Tá pegando fogo. - o falante aponta o local que está em chamas

(15) Bravo! - o falante está aplaudindo ${ }^{26}$

(16) Psiu! - o falante está com o dedo indicador na boca

(17) Fora! - o falante está apontando para algum lugar fora do ambiente em que está

(18) Silêncio! - o falante está com o dedo indicador na boca

Esses casos ilustram cenários em que as interjeições são acompanhadas de gestos ou apontamentos que agregam informações na composição semântica do item ${ }^{27}$.

O próximo critério que usaremos é a repetibilidade. Trata-se de um dos testes que Potts $(2007,2005)$ aplica para identificar expressivos. Algumas interjeições podem ser repetidas em sequência, gerando um efeito de intensificação do seu significado, sem produzir redundância. Do nosso inventário, as interjeições em que pode ocorrer repetição são: 'avante!', 'ai!', 'ui!', 'cuidado!', 'atenção!', 'bravo!' ‘vamos!' e 'calma!'. Vejamos alguns exemplos:

(19) Avante! Avante! (um amigo incentivando o outro)

(20) Ai! Ai! Ai! (quando alguém se machuca)

(21) Cuidado! Cuidado! (João chamando atenção de Mario para não derrubar os copos)

(22) Atenção! Atenção! (carro de som na rua fazendo propaganda)

(23) Bravo! Bravo! (após uma apresentação de teatro)

25 Por exemplo, demonstrativos com usos dêiticos só podem receber uma interpretação quando consideramos o apontamento que o acompanha, pois ele determinará qual é seu referente no contexto.

26 Para esta interjeição em particular, como levar o dedo a boca em "psiu!", há um gesto peculiar que é bater palmas.

27 Podem ocorrer casos em que uma mesma interjeição pode ter sentidos diferentes se vier ou não acompanhada de gestos. Considere 'psiuu!' (longo); nesse caso, a prosódia produz um efeito de chamar alguém, ao contrário do que vemos no exemplo (26). 
(24) Psiu! Psiu! (chamando alguém)

Por outro lado, nem todas as interjeições se encaixam nesse critério, e assim se formos usá-las repetidas vezes, o resultado será estranho ${ }^{28}$ :

(25) \# Ufa! Ufa! Me dei bem na prova.

(26) \# Puxa! Puxa! Ganhei o prêmio da rifa.

(27) \# Caramba! Caramba! Que bom que te encontrei.

Ainda que nem todas as interjeições possam se repetir produzindo um efeito de intensificação do seu sentido, isso não significa que esses itens são algum tipo de exceção e que não possuam conteúdo expressivo; ao contrário, essas interjeições passam nos outros testes e, o mais relevante, não podem ser avaliadas pelas condições de verdade, já que não possuem conteúdo descritivo.

Por fim, o último critério de classificação é se a interjeição possui mais de um significado. Por todos os critérios de classificação que passamos até momento, não é a primeira vez que vamos esbarrar na multiplicidade de sentidos de uma mesma interjeição. Segundo a nossa seleção, as interjeições que cabem nesse critério são:

Quadro 6. Interjeições que possuem mais de um significado

\begin{tabular}{|l|l|}
\hline $\begin{array}{l}\text { Interjeições que possuem } \\
\text { mais de um significado }\end{array}$ & $\begin{array}{l}\text { 'psiu!', 'ah!', 'puxa!', 'ai!', 'ui!', 'oh!', 'putz!', 'vixe!', 'opa!' } \\
\text { e 'caramba!' }\end{array}$ \\
\hline
\end{tabular}

Fonte: Elaboração própria

Vejamos alguns exemplos de diversos sentidos da interjeição 'ai!':

(28) Ai! Esqueci minhas chaves. (expressiva cognitiva)

(29) Ai! Bati eu braço. (expressiva emotiva - dor)

(30) Ai! Pega a roupa do varal que começou a chover. (expressiva cognitiva)

(31) Ai! Que pena que perdi o dinheiro (expressiva emotiva - decepção)

(32) Ai! Que susto (expressiva emotiva - medo)

A interjeição 'ai!' é um exemplo claro de como um item pode ter diferentes funções nas variadas situações de uso, pois pode ser cognitiva e emotiva e, dentro das emoções, pode expressar vários (sub)tipos.

28 Pode haver variação dialetal na aceitação sobre quais interjeições podem se repetir. 
Como hipótese, temos que as interjeições secundárias, em princípio, possuem um significado mais estável, pois, dado que pertencem a outra classe gramatical, seu uso como interjeição guarda algo de seu sentido original. Então, seguindo esse raciocínio, as interjeições primárias são mais suscetíveis a produzirem mais de um significado; isso, porém, não é uma regra, pois temos as interjeições 'oba!', 'arre!', 'tomara!', 'ufa!', 'bravo!', que são primárias e possuem apenas um sentido.

Vejamos, a seguir, o último conjunto de critério que propomos para classificar as interjeições, que têm a ver com o caráter indexical das interjeições.

\subsection{Critérios baseados nas coordenadas contextuais}

Sendo as interjeições indexicais, uma pergunta natural a se fazer é "quais coordenadas contextuais são mobilizadas por uma dada interjeição?". Vimos que um contexto kaplaniano pode ser expresso como $\left\langle\mathrm{C}_{\mathrm{a}^{\prime}} \mathrm{C}_{\mathrm{o}^{\prime}} \mathrm{C}_{\mathrm{t}^{\prime}} \mathrm{C}_{\mathrm{y}^{\prime}} \mathrm{C}_{\mathrm{d}^{\prime}} \mathrm{C}_{\mathrm{w}}>\right.$, que representam respectivamente agente, ouvinte, tempo, lugar, conjunto de demonstrata e mundos do contexto. Vimos também que 'oba' recupera a coordenada $\mathrm{c}_{\mathrm{a}}$ de agente do contexto. Por sua vez, uma interjeição como 'fora' recupera um agente $\left(\mathrm{c}_{\mathrm{a}}\right)$, um (ou mais) ouvinte $(\mathrm{s})\left(\mathrm{c}_{\mathrm{o}}\right)$ e também lida com a coordenada $c_{t}$ de lugar do contexto; já a interjeição 'tomara', ao lidar com mundos possíveis (potencialmente) diferentes daquele do proferimento, mobiliza a coordenada de mundo do contexto $\left(\mathrm{c}_{\mathrm{w}}\right)$, além da de agente do contexto ${ }^{29}$.

O quadro abaixo traz uma classificação das interjeições segundo as coordenadas contextuais que mobilizam, e, na próxima seção, teremos todos os critérios agrupados:

Quadro 7. As interjeições e coordenadas contextuais

\begin{tabular}{|l|l|l|l|l|l|l|l|l|l|l|l|l|l|l|}
\hline & $\mathrm{C}_{\mathrm{a}}$ & $\mathrm{C}_{\mathrm{o}}$ & $\mathrm{C}_{\mathrm{t}}$ & $\mathrm{C}_{\mathrm{l}}$ & $\mathrm{C}_{\mathrm{d}}$ & $\mathrm{C}_{\mathrm{w}}$ & & & $\mathrm{C}_{\mathrm{a}}$ & $\mathrm{C}_{\mathrm{o}}$ & $\mathrm{C}_{\mathrm{t}}$ & $\mathrm{C}_{\mathrm{l}}$ & $\mathrm{C}_{\mathrm{d}}$ & $\mathrm{C}_{\mathrm{w}}$ \\
\hline Viva! & $\mathrm{X}$ & & $\mathrm{X}$ & & & & Oh! & $\mathrm{X}$ & $\mathrm{X}$ & $\mathrm{X}$ & & & \\
\hline Psiu! & $\mathrm{X}$ & $\mathrm{X}$ & $\mathrm{X}$ & & $\mathrm{X}$ & & Ufa! & $\mathrm{X}$ & & $\mathrm{X}$ & & & \\
\hline Avante! & $\mathrm{X}$ & $\mathrm{X}$ & $\mathrm{X}$ & $\mathrm{X}$ & & & Bravo! & $\mathrm{X}$ & $\mathrm{X}$ & $\mathrm{X}$ & & $\mathrm{X}$ & \\
\hline Ah! & $\mathrm{X}$ & & $\mathrm{X}$ & & & & & Pois sim/não & $\mathrm{X}$ & $\mathrm{X}$ & $\mathrm{X}$ & & & \\
\hline Oba! & $\mathrm{X}$ & & $\mathrm{X}$ & & & & Silêncio! & $\mathrm{X}$ & $\mathrm{X}$ & $\mathrm{X}$ & $\mathrm{X}$ & $\mathrm{X}$ & \\
\hline Fora! & $\mathrm{X}$ & $\mathrm{X}$ & $\mathrm{X}$ & $\mathrm{X}$ & $\mathrm{X}$ & & & Toca! & $\mathrm{X}$ & $\mathrm{X}$ & $\mathrm{X}$ & $\mathrm{X}$ & & \\
\hline Puxa! & $\mathrm{X}$ & & $\mathrm{X}$ & & & & Calma! & $\mathrm{X}$ & $\mathrm{X}$ & $\mathrm{X}$ & & & \\
\hline
\end{tabular}

(continua)

29 É importante salientar que não descreveremos o conteúdo expressivo de cada interjeição com que analisamos, pois isso seria um trabalho à parte. Seja como for, a informação contextual indicada é mobilizada pelo predicado expressivo que está associado às interjeições. Assim, mesmo uma interjeição como 'raios!' envolve ao menos $\mathrm{c}_{\mathrm{a}}$ e $\mathrm{c}_{\mathrm{t}^{\prime}}$ para indicar que $\mathrm{c}_{\mathrm{a}}$ está descontente em $\mathrm{c}_{\mathrm{t}}$. 


\begin{tabular}{|l|l|l|l|l|l|l|l|l|l|l|l|l|l|l|}
\hline Arre! & X & & X & & & & Putz! & X & & X & & & \\
\hline Tomara! & X & X & X & & & X & Vixe! & X & & X & & & \\
\hline Ai! & X & & X & & & & Coragem! & X & X & X & & & \\
\hline Ui! & X & & X & & & & Força! & X & X & X & & & \\
\hline Credo! & X & & X & & & & Hã-hã! & X & X & X & & & \\
\hline Cuidado! & X & X & X & X & X & & Opa! & X & & X & & & \\
\hline Atenção! & X & X & X & X & & & Raios! & X & & X & & & \\
\hline Vamos! & X & X & X & X & & & Caramba! & X & & X & & & \\
\hline
\end{tabular}

Fonte: Elaboração própria

\section{Uma tipologia linguística para as interjeições do PB}

Abaixo, temos um quadro geral que leva em conta os critérios de classificação vistos nas seções 2.1, 2.2 e 2.3 aplicados às 30 interjeições selecionadas:

Quadro 8. Quadro geral das interjeições

\begin{tabular}{|l|l|l|l|l|l|l|l|l|l|l|l|l|l|l|l|l|}
\hline & $\mathrm{P}$ & $\mathrm{S}$ & $\mathrm{EM}$ & $\mathrm{CG}$ & $\mathrm{CN}$ & $\mathrm{FT}$ & $\mathrm{CM}$ & $\mathrm{AP}$ & $\mathrm{RP}$ & $+\mathrm{S}$ & $\mathrm{C}_{\mathrm{a}}$ & $\mathrm{C}_{\mathrm{o}}$ & $\mathrm{C}_{\mathrm{t}}$ & $\mathrm{C}_{\mathrm{l}}$ & $\mathrm{C}_{\mathrm{d}}$ & $\mathrm{C}_{\mathrm{w}}$ \\
\hline Viva! & & $\mathrm{X}$ & $\mathrm{X}$ & & & & & & & & $\mathrm{X}$ & & $\mathrm{X}$ & & & \\
\hline Psiu! & $\mathrm{X}$ & & & $\mathrm{X}$ & $\mathrm{X}$ & & & $\mathrm{X}$ & & $\mathrm{X}$ & $\mathrm{X}$ & $\mathrm{X}$ & $\mathrm{X}$ & & $\mathrm{X}$ & \\
\hline Avante! & & $\mathrm{X}$ & $\mathrm{X}$ & & $\mathrm{X}$ & & & & $\mathrm{X}$ & & $\mathrm{X}$ & $\mathrm{X}$ & $\mathrm{X}$ & $\mathrm{X}$ & & \\
\hline Ah! & $\mathrm{X}$ & & & $\mathrm{X}$ & & $\mathrm{X}$ & & & & $\mathrm{X}$ & $\mathrm{X}$ & & $\mathrm{X}$ & & & \\
\hline Oba! & $\mathrm{X}$ & & $\mathrm{X}$ & & & & & & & & $\mathrm{X}$ & & $\mathrm{X}$ & & & \\
\hline Fora! & & $\mathrm{X}$ & & & $\mathrm{X}$ & & & $\mathrm{X}$ & & & $\mathrm{X}$ & $\mathrm{X}$ & $\mathrm{X}$ & $\mathrm{X}$ & $\mathrm{X}$ & \\
\hline Puxa! & $\mathrm{X}$ & & $\mathrm{X}$ & $\mathrm{X}$ & & & & & & $\mathrm{X}$ & $\mathrm{X}$ & & $\mathrm{X}$ & & & \\
\hline Arre! & $\mathrm{X}$ & & $\mathrm{X}$ & & & & & & & & $\mathrm{X}$ & & $\mathrm{X}$ & & & \\
\hline Tomara! & $\mathrm{X}$ & & & & $\mathrm{X}$ & & $\mathrm{X}$ & & & & $\mathrm{X}$ & $\mathrm{X}$ & $\mathrm{X}$ & & & $\mathrm{X}$ \\
\hline Ai! & $\mathrm{X}$ & & $\mathrm{X}$ & $\mathrm{X}$ & & & & & $\mathrm{X}$ & $\mathrm{X}$ & $\mathrm{X}$ & & $\mathrm{X}$ & & & \\
\hline Ui! & $\mathrm{X}$ & & $\mathrm{X}$ & $\mathrm{X}$ & & & & & $\mathrm{X}$ & $\mathrm{X}$ & $\mathrm{X}$ & & $\mathrm{X}$ & & & \\
\hline Credo! & & $\mathrm{X}$ & $\mathrm{X}$ & & & & & & & & $\mathrm{X}$ & & $\mathrm{X}$ & & & \\
\hline Cuidado! & & $\mathrm{X}$ & & & $\mathrm{X}$ & & & $\mathrm{X}$ & $\mathrm{X}$ & & $\mathrm{X}$ & $\mathrm{X}$ & $\mathrm{X}$ & $\mathrm{X}$ & $\mathrm{X}$ & \\
\hline Atenção! & & $\mathrm{X}$ & & & $\mathrm{X}$ & & & & $\mathrm{X}$ & & $\mathrm{X}$ & $\mathrm{X}$ & $\mathrm{X}$ & $\mathrm{X}$ & & \\
\hline Vamos! & & $\mathrm{X}$ & & & $\mathrm{X}$ & & & & $\mathrm{X}$ & & $\mathrm{X}$ & $\mathrm{X}$ & $\mathrm{X}$ & $\mathrm{X}$ & & \\
\hline Oh! & $\mathrm{X}$ & & & & & $\mathrm{X}$ & & & & $\mathrm{X}$ & $\mathrm{X}$ & $\mathrm{X}$ & $\mathrm{X}$ & & & \\
\hline Ufa! & $\mathrm{X}$ & & $\mathrm{X}$ & & & & & & & & $\mathrm{X}$ & & $\mathrm{X}$ & & & \\
\hline Bravo! & $\mathrm{X}$ & & & & $\mathrm{X}$ & & & $\mathrm{X}$ & $\mathrm{X}$ & & $\mathrm{X}$ & $\mathrm{X}$ & $\mathrm{X}$ & & $\mathrm{X}$ & \\
\hline
\end{tabular}




\begin{tabular}{|c|c|c|c|c|c|c|c|c|c|c|c|c|c|c|}
\hline $\begin{array}{l}\text { Pois sim/ } \\
\text { não }\end{array}$ & $x$ & & & & $x$ & $x$ & & & & $x$ & $x$ & $x$ & & \\
\hline Silêncio! & & $X$ & & & $x$ & & $x$ & & & $x$ & $x$ & $x$ & $x$ & $x$ \\
\hline Toca! & & $X$ & & & $X$ & & & & & $x$ & $X$ & $x$ & $x$ & \\
\hline Calma! & & $X$ & $X$ & & $x$ & & & $X$ & & $x$ & $X$ & $x$ & & \\
\hline Putz! & $x$ & & $X$ & & & & & & $x$ & $x$ & & $x$ & & \\
\hline Vixe! & $x$ & & $x$ & $x$ & & & & & $X$ & $x$ & & $x$ & & \\
\hline Coragem! & & $X$ & & & $X$ & & & & & $X$ & $X$ & $X$ & & \\
\hline Força! & & $X$ & & & $x$ & & & & & $x$ & $x$ & $x$ & & \\
\hline Hã-hã! & $x$ & & & & $X$ & $x$ & & & & $X$ & $X$ & $X$ & & \\
\hline Opa! & $x$ & & $X$ & $X$ & & & & & $X$ & $X$ & & $X$ & & \\
\hline Raios! & & $X$ & $X$ & & & & & & & $X$ & & $X$ & & \\
\hline Caramba! & $x$ & & $X$ & $x$ & & & & & $X$ & $X$ & & $X$ & & \\
\hline
\end{tabular}

Fonte: Elaboração própria

Legenda: P: interjeições primárias / S: interjeições secundárias / EM: emotivas / CG: cognitivas / CN: conotativas / FT: fáticas / CM: seleciona complemento / AP: acompanha gestos / RP: repetição / +S: possui mais de um significado.

O quadro acima mostra que todas as interjeições estão ligadas ao falante e ao tempo do contexto - isso explica por que elas são "imediatas" assim como verbos performativos, pois basta pronunciá-las para que seu conteúdo (expressivo) seja efetivado, do mesmo que basta usar 'prometer' (com sinceridade) para termos uma promessa. O imediatismo das interjeições tem então a ver com sua ligação ao tempo e ao agente do contexto.

Fica claro também que a variedade de funções das interjeições, não sendo, portanto, razoável dizer que elas "expressam emoções" - somente algumas fazem isso, e a funcionalidade das interjeições é muito mais rica. A variedade de informações indexicais que as interjeições mobilizam também evidencia como elas têm conteúdos (expressivos) variados, podendo ser empregadas para atuar sobre um ouvinte, levar em conta o lugar do contexto de fala ou mesmo mundos possíveis diferentes.

Certamente alguns critérios devem mais aprofundados - como a ideia de pedir complemento, por exemplo, pode ser refinada com relação ao tipo de complemento e sua natureza, bem como o papel de gestos e apontamentos, que aqui consideramos como iguais -, e outros critérios podem ser propostos. Mas, seja como for, nossa classificação é baseada em critérios linguísticos, com lastros teóricos e empíricos, e permitem um olhar mais rico sobre o funcionamento dessa classe ainda pouco estudada. 


\section{Conclusão}

Neste artigo, nosso intuito foi apresentar uma forma de análise, tratamento e classificação das interjeições do PB nos moldes da descrição linguística formal. Tratamos as interjeições como sentenças independentes, com conteúdo expressivo, que possuem elementos indexicais em sua estrutura recuperados no contexto de fala.

Para tanto, nos pautamos nas ideias de Wilkins (1992), associada às ideias sobre indexicais encontradas em Kaplan (1989). Kaplan (2004), Potts $(2007,2005)$ e Gutzmann $(2019,2015)$ defendem que as interjeições contribuem numa dimensão uso-funcional, ou seja, esses itens não podem ser avaliados pelas condições de verdade, mas feliz ou infeliz num dado contexto de uso.

Diante de tal análise para as interjeições, podemos classificá-las com base em critérios linguísticos. Primeiramente, revisitamos a classificação de Ameka (1992) de interjeição primária e secundária, e a classificação segundo as funções comunicativas desses itens, que são: emotiva, cognitiva e fática; e os outros critérios levam em consideração o contexto de fala kaplaniano das interjeições, e também (i) selecionar complemento, (ii) ser acompanhada de gestos ou apontamentos, (iii) repetibilidade, e (iv) possuir mais de um significado.

Por meio do exercício de aplicar critérios relacionados ao contexto de fala e à funcionalidade das interjeições, conseguimos entender um pouco mais sobre a classe das interjeições e alguns casos particulares, sendo que alguns critérios só se aplicam a algumas interjeições e não a outras. Além disso, esta pesquisa suscitou outros temas relacionados às interjeições, como desenvolver pontos comparativos entre as interjeições e imperativos, bem como buscar outros critérios de classificação. Notamos finalmente que o presente trabalho não apenas traz uma hipótese para o funcionamento das interjeições, mas também levanta novas perguntas para uma classe de palavras ainda muito pouco investigada.

\section{Referências}

AMEKA, F. Interjections: The universal yet neglected part of speech. Journal of Pragmatics, v. 18, p. 101-118, 1992.

AMEKA, F. Interjections. Encyclopedia of language \& linguistics. Oxford: Elsevier, 2006. p. $743-746$. 
- | Uma tipologia para as interjeições do português brasileiro

BASSO, R.; TEIXEIRA, A. Interjeições indexicais expressivas: uma proposta de tratamento em semântica formal. Revista Veredas Online, v. 21, Issue 2, p. 78-94, 2017.

CIPRO NETO, P. Gramática da língua portuguesa. São Paulo: Scipione, 1998.

DE NICOLA, J.; INFANTE, U. Gramática contemporânea da língua portuguesa. São Paulo: Scipione, 1997.

FARACO, C. E.; MOURA, F. M.; MARUXO JR, J. H. Gramática. São Paulo: Ática, 2007.

FORTIN, A. The Morphology and Semantics of Expressive Affixes. 2011. Tese (Doutorado em Filosofia) - Universidade de Oxford, Oxford, 2011.

FREITAG, R. M. K. Marcadores discursivos não são vícios de linguagem. Interdisciplinar: Revista de Estudos em Língua e Literatura, v. 4, p. 22-43, 2007.

GOFFMAN, E. Forms of talk. Oxford: Blackwell, 1981.

GUTZMANN, D. Use-Conditional Meaning. Studies in Multidimensional Semantics. (Oxford Studies in Semantics and Pragmatics 6). Oxford: Oxford University Press, 2015.

GUTZMANN, D. The Grammar of Expressivity. Oxford: Oxford University Press, 2019.

KAPLAN, D. Demonstratives. In: ALMOG, J.; PERRY, J.; WETTSTEIN, H. (ed.). Themes from Kaplan. New York: Oxford University Press, 1989/1977. p. 481-563.

KAPLAN, D. The meaning of ouch and oops. LosAngeles:University of California.2004/1999. Palestra. Disponível em: https://www.youtube.com/watch?v=iaGRLlgPI6w\&t=84s. Acesso em: 15 dez. 2019.

POTTS, C. The Logic of Conventional Implicatures. Oxford: Oxford University Press, 2005.

POTTS, C. The expressive dimension. Theoretical Linguistics, v. 33, n. 2, p. 165-197, 2007.

SARMENTO, L. L. Gramática em textos. 2. ed. rev. São Paulo: Moderna, 2005. 
SCHLENKER, P. Indexicality and De Se Reports, 2010. Disponível em: https://files.nyu. edu/pds4/public/Schlenker-Indexicality_and_De_Se.pdf. Acesso em: 15 dez. 2019.

TEIXEIRA, A. As interjeições do português brasileiro e seus aspectos indexicais. 2019. Dissertação (Mestrado em Linguística) - Centro de Educação e Ciências Humanas, Universidade Federal de São Carlos, São Carlos, 2019.

TEIXEIRA, L. R. Indexicais e operadores-monstros no português brasileiro. 2012. Dissertação (Mestrado em Linguística) - Centro de Comunicação e Expressão, Universidade Federal de Santa Catarina, Florianópolis, 2012.

WIERZBICKA, A. The semantics of interjection. Journal of Pragmatics, v. 18, p. 159-192, 1992.

WILKINS, D. Interjections as deictics. Journal of Pragmatics, v. 18, p. 119-158, 1992.

COMO CITAR ESTE ARTIGO: BASSO, Renato Miguel; TEIXEIRA, Ariane. Uma tipologia para as interjeições do português brasileiro. Revista do GEL, v. 16, n. 3, p. 10-34, 2019. Disponível em: https://revistadogel.gel.org.br/

DOI: http://dx.doi.org/10.21165/gel.v16i3.2593

Submetido em: 28/10/2019 | Aceito em: 29/11/2019. 